YUYAMA, L.K.O.; AGUIAR, J.P.L.; YUYAMA, K.; MACEDO, S.H.M.; FÁVARO, D.I.T.; AFONSO, C.; VASCONCELLOS, M.B.A. Determinação de elementos essenciais e não essenciais em palmito de pupunheira. Horticultura Brasileira, Brasilia, v. 17, n. 2, p. 91-95, julho, 1999.

\title{
Determinação de elementos essenciais e não essenciais em palmito de pupunheira.
}

\author{
Lucia K.O. Yuyama $^{1}$; Jaime P.L. Aguiar ${ }^{1}$; Kaoru Yuyama $^{1}$; Sonja H.M. Macedo $^{1}$; Déborah I.T. Fávaro ${ }^{2}$; \\ Claudia Afonso²; Marina B.A. Vasconcellos ${ }^{2}$. \\ ${ }^{1}$ INPA-CPCS-CPCA, C. Postal 478, 69011-970 Manaus-AM; ${ }^{2}$ IPEN-CNEN, C. Postal 11049, 05.422-970 São Paulo-SP.
}

\section{RESUMO}

Considerando-se a atual situação epidemiológica do Brasil em que a obesidade e as doenças crônico-degenerativas (doenças cardiovasculares, diabetes mellitus e câncer) passam a ser destaque em saúde pública, parece prudente a preocupação quanto à caracterização química dos alimentos regionais com potencial econômico e nutricional, em especial os de baixo teor calórico, como o palmito. Sendo assim, determinou-se a composição centesimal, fitato e elementos minerais (macro e micro) no palmito de pupunheira in natura e cozido. O palmito de pupunheira utilizado foi o da raça Pampa Hermosa, da Estação Experimental de Fruticultura da Coordenação de Pesquisas em Ciências Agronômicas (CPCA) do Instituto Nacional de Pesquisas da Amazônia (INPA), em Manaus (AM), coletado no período chuvoso, em janeiro de 1995 . Tomou-se aleatoriamente $3,5 \mathrm{~kg}$ de palmito de 110 progênies de pupunha inerme, com 2 anos de idade, por ocasião do primeiro corte. As palmeiras foram cultivadas em Latossolo Amarelo, isento de adubação. As análises químicas foram efetuadas no Laboratório de Nutrição e Físico-Química dos Alimentos do INPA e IPEN-CNEN. De acordo com os resultados obtidos, verificou-se que o palmito, in natura e cozido, apresentou em $100 \mathrm{~g}$ da parte comestível respectivamente, alto teor de umidade, em torno de $90 \% ; 1,5 \mathrm{~g}$ de proteínas; baixo teor de lipídio $(0,3$ e $0,2 \mathrm{~g})$ e; concentrações importantes de fibra alimentar $(3,8$ e 2,2 g). Em relação aos elementos minerais nutricionalmente importantes sobressairam, também em $100 \mathrm{~g}$ da parte comestível, K (194,0 $\mathrm{mg}$; 128,0 mg); Ca (42,4 mg ; 42,9 mg); $\mathrm{Mg}$ (3,4 mg; 2,2 mg); Fe $(237,7 \mu \mathrm{g} ; 265,2 \mu \mathrm{g})$, Se $(2,1 \mu \mathrm{g} ; 2,8 \mu \mathrm{g})$, respectivamente no palmito in natura e cozido. Dos elementos minerais não essenciais na alimentação, destacaram-se o bromo $(830,4 \pm 5,8 \mu \mathrm{g} \% ; 434 \pm 5,8 \mu \mathrm{g} \%)$ e o rubídio $(315,2 \pm 3,2 \mu \mathrm{g} \% ; 433,5 \pm 34,0 \mu \mathrm{g} \%)$ respectivamente para palmito in natura e cozido. A concentração de fitato (hexafosfato de mioinositol) foi de $554,7 \mathrm{mg} \%$ para o palmito in natura e $379,1 \mathrm{mg} \%$, para o palmito cozido. Apesar do palmito ser um alimento dietético sob o ponto de vista nutricional, devido à baixa concentração em calorias e à presença de fibra, o mesmo pode contribuir no aporte de minerais essenciais na alimentação da população Amazônica.

Palavras-chave: Bactris gasipaes, minerais, fibra, composição centesimal, fitato.

\begin{abstract}
Determination of essential and non-essential elements in palm heart of peach palm.
\end{abstract}

In recent years, there has been a steady increase in the ocurrence of obesity and chronic or degenerative diseases (cardiovascular, diabetes mellitus, cancer) in Brazil. Therefore, studies on the nutritional composition of regional foodstuffs, especially those with low calorific content and high commercial value, are highly justified. The aim of this study was to evaluate the centesimal phytate and mineral micro or macroelement composition of in natura or cooked palm heart of peach palm (Pampa Hermosa race), collected in January 1995 (rainy season) in the fruit experimental station of the Coordenação de Pesquisas em Ciências Agronômicas (CPCA), Instituto Nacional de Pesquisas da Amazônia (INPA), in Manaus, Brazil. Chemical analyses were conducted on a total of $3.5 \mathrm{~kg}$ of plant heart samples, taken at random from 110 spineless progeny from Yurimáguas, Peru, which were grown on non-fertilized soil. Analyses were conducted in the Nutrition and Food PhysicoChemical laboratory of INPA and IPEN-CNEN. Each $100 \mathrm{~g}$ of the edible part of in natura or cooked palm heart provided low concentrations of lipids ( 0.3 and $0.2 \mathrm{~g}$, respectively) and high concentrations of fibre (3.8 and 2.2, respectively). Both type of palm heart contained (in $100 \mathrm{~g}$ ): $90 \%$ humidity and $1.5 \mathrm{~g}$ protein. The results for nutritionally important minerals were as follows (in 100 $\mathrm{g}$ of in natura or cooked palm heart, respectively): K (194.0 mg; $128.0 \mathrm{mg}$ ), Ca (42.4 mg; $42.9 \mathrm{mg}), \mathrm{Mg}$ (3.4 mg; $2.2 \mathrm{mg}), \mathrm{Fe}(237.7$ $\mu \mathrm{g} ; 265.2 \mu \mathrm{g})$, and Se $(2.1 \mu \mathrm{g}: 2.8 \mu \mathrm{g})$. The concentrations of non essential elements minerals in in natura and cooked palm heart were, respectively, as follows: bromine $(830.4 \pm 5.8 \mu \mathrm{g} \%$; $434.0 \pm 5.8 \mu \mathrm{g} \%)$ and rubidium $(315.2 \pm 3.2 \mu \mathrm{g} \% ; 433.5 \pm 34.0 \mu \mathrm{g} \%)$. The concentration of phytate in $100 \mathrm{~g}$ of palm heart, was as follows: $554.7 \mathrm{mg}$ (in natura) $379.1 \mathrm{mg}$ (cooked). Although palm heart can be considered a dietetic foodstuff, being rich in fibre and low in calories, it can be recommended as a good source of minerals for the Amazonian populations.

Keywords: Bactris gasipaes, mineral, fiber, centesimal composition, phytate.

\section{(Aceito para publicação em 22 de março de 1999)}

\begin{abstract}
$\mathrm{A}$ pupunheira (Bactris gasipaes Kunth) é uma palmeira caespitose, em que todas as partes da planta são utilizadas, embora sejam mais importantes os frutos e o palmito, com grande potencial de mercado (Clement \& Mora Urpí, 1987). O palmito é retirado da parte central e gema apical da estipe da palmeira e das regiões acima e abaixo,
\end{abstract}

correspondendo às folhas macias em crescimento (Araújo, 1993). De sabor agradável e tenro o palmito fresco pode ser consumido in natura ou cozido em água com limão e sal, ou até mesmo assado no forno e na forma de conserva (Kerr et al., 1997). O palmito de pupunha, fresco ou cozido, serve para todas as receitas em que se usam os pal- mitos de outras palmeiras (Kerr et al., 1997).

Há um significativo mercado consumidor de palmito em geral, com uma quantidade média de 9,0 mil toneladas por ano e um rendimento em torno de US\$ 3,6 por quilo do produto, industrializado e comercializado no atacado (Bonanccini, 1997). A quase totalidade 
do que se industrializa atualmente corresponde à exploração predatória dos palmitos açaí (Euterpe oleracea) e juçara (Euterpe edulis). Porém com o aumento da fiscalização sobre estas extrações, espera-se uma diminuição na oferta do palmito in natura, o que justifica o cultivo comercial da pupunha (Bonanccini, 1997). A pupunheira para produção de palmito, em especial a raça Pampa Hermosa, é uma alternativa de cultivo em várias regiões do Brasil, cujas vantagens são a precocidade, com o primeiro corte acontecendo a partir de 18 meses após o plantio; perfilhamento, com possibilidade de novos cortes nos anos seguintes, sem necessidade de replantio; qualidade do palmito e; facilidade no trato cultural e corte, já que as plantas não possuem espinhos (Yuyama, 1996). Uma outra característica marcante da pupunheira, é o seu carácter ecológico, ou seja, a palmeira pode ser cultivada em áreas agrícolas, pastagens ou capoeira, sem danos às florestas nativas, possibilitando reflorestamento e um planejamento da agroindústria, com programação de produção de palmito (Nishikawa et al., 1998).

Considerando essa perspectiva de mercado e, consequentemente, o consumo, a preocupação quanto ao aspecto nutricional do palmito, que apresenta baixo teor calórico, além de conter elementos minerais (Araújo, 1993), se faz necessária, uma vez que na atual fase de transição epidemiológica do Brasil, a obesidade e as doenças crônicodegenerativas (doenças cardiovasculares, diabetes mellitus e câncer) passam a ter destaque em questões de saúde pública (Dutra de Oliveira \& Marchini, 1998). Entretanto, o tipo e condições do solo, localização geográfica, clima, diferentes raças de palmito e procedimentos analíticos utilizados, podem interferir no conteúdo de minerais. Embora se reconheça a essencialidade de 21 elementos minerais na nutrição humana, nem todos apresentam registros de deficiência devido à sua ampla distribuição entre diferentes tipos de alimentos (Hazzel, 1985). O interesse na determinação de vários elementos essenciais e não essenciais em alimentos e dietas, do ponto de vista nutricional, está focalizado principalmente na adequação de nutrientes essenciais, assim como no monitoramento de dietas e alimentos em relação ao conteúdo de elementos tóxicos (Chatt et al., 1988).

Considerando que pouco se sabe sobre a composição de elementos minerais na maioria das olerícolas da região Amazônica, em especial em palmito, o objetivo deste trabalho foi determinar os elementos minerais essenciais ( $\mathrm{Na}, \mathrm{K}, \mathrm{Ca}, \mathrm{Mg}, \mathrm{Zn}, \mathrm{Fe}, \mathrm{Se}, \mathrm{Cr}$ e $\mathrm{Co})$ e não essenciais ( $\mathrm{Br}, \mathrm{Eu}$ e Rb), assim como a composição centesimal, incluindo a quantificação de fibra alimentar solúvel e insolúvel e fitato, no palmito de pupunheira in natura e cozido.

\section{MATERIAL E MÉTODOS}

O palmito de pupunheira, raça Pampa Hermosa, foi coletado na Estação Experimental de Fruticultura da Coordenação de Pesquisas em Ciências Agronômicas (CPCA) do Instituto Nacional de Pesquisas da Amazônia (INPA), situada na BR 174, km 45, Manaus (AM), no período chuvoso (inverno do Amazonas), ou seja, janeiro de 1995. Tomou-se aleatoriamente, $3,5 \mathrm{~kg}$ de palmito de 110 progênies de pupunha inerme, provenientes de Yurimáguas, Peru. As plantas apresentavam dois anos de idade, estavam no primeiro corte e foram cultivadas em Latossolo Amarelo, isento de adubação (Yuyama, 1995).

Os palmitos foram analisados no Laboratório de Nutrição da Coordenação de Pesquisas em Ciências da Saúde (CPCS), nas formas in natura e cozido em temperatura de ebulição, por 50 minutos. A determinação da umidade foi realizada em estufa com circulação forçada de ar, a $60^{\circ} \mathrm{C}$, até peso constante. Em seguida, os palmitos secos foram pulverizados e analisados quimicamente, com quantidades específicas para cada análise, conforme descrição nos diferentes métodos utilizados. A análise da composição centesimal foi realizada de acordo com a metodologia da AOAC (1995). A determinação do teor de proteínas foi feita pelo método de Kjeldahl (micro) para nitrogênio total, utilizando-se o fator 6,25 para transformação em proteína. A fração extrato etéreo foi determinada em extrator intermitente de soxhlet, utilizando-se éter de petróleo P.A., como solvente. A determinação da fibra alimentar solúvel e insolúvel foi feita pelo método enzimático-gravimétrico de Asp et al. (1983). Esta metodologia permite avaliar, separadamente, o conteúdo de fibra alimentar solúvel e insolúvel. O teor de glicídio foi determinado por diferença após a determinação das frações anteriores. O valor calórico da dieta regional foi calculado a partir dos teores da fração proteica, lipídica e glicídica, utilizando-se os coeficientes específicos que levam em consideração o calor de combustão 4,0; 9,0 e 4,0 kcal respectivamente. A determinação do teor do fitato seguiu o método colorimétrico de Thompson \& Erdman (1982), modificado por Lajolo et al. (1991). Após extração, o fósforo foi determinado pelo método de Fiske \& Subbarow (1925). No cálculo foi utilizado o fator de conversão 3,55 , uma vez que o fitato possui $28,2 \%$ de fósforo. A quantificação de elementos minerais foi realizada na Supervisão de Radioquímica do IPENCNEN, por Ativação com Nêutrons Instrumental (AANI). Os padrões sintéticos dos elementos (Ca, Fe, K, Na, Se e $\mathrm{Zn}$ ) foram preparados de acordo com as descrições no trabalho de Yuyama et al. (1997). Os padrões sintéticos dos elementos ( $\mathrm{Mg}, \mathrm{Br}, \mathrm{Co}, \mathrm{Cr}, \mathrm{Eu}$ e $\mathrm{Rb}$ ) foram preparados respectivamente, dissolvendo-se óxido de magnésio, espectroscopicamente puro, em ácido nítrico diluído; brometo de potássio, em água destilada à temperatura ambiente; cobalto, com 99,995\% de pureza, em ácido nítrico diluído a frio; cromo metálico, em ácido fluorídrico sob aquecimento à baixa temperatura, com a posterior adição de ácido sulfúrico concentrado; óxido de európio, que foi calcinado por duas horas a $800^{\circ} \mathrm{C}$ e posteriormente dissolvido em ácido nítrico a quente; cloreto de rubídio, em água destilada à temperatura ambiente; óxido de escândio com 99,9\% de pureza em ácido nítrico concentrado a quente.

Para a preparação de amostras e padrões para irradiação, foram pesados cerca de $200 \mathrm{mg}$ do palmito in natura e cozido e do material de referência em envelopes de polietileno, previamente limpos com ácido nítrico diluído e os padrões sintéticos dos elementos de inte- 
resse. Em sequência, amostras, material de referência e padrões sintéticos foram irradiados no reator de pesquisa IEA-R1 do Instituto de Pesquisas Energéticas e Nucleares/Comissão Nacional de Energia Nuclear-SP (IPEN/ CNEN-SP). As amostras e os padrões foram submetidos a dois tipos de irradiação, de acordo com a meia-vida do radioisótopo de interesse:

a) irradiações curtas: as amostras e padrões foram irradiados por dois minutos, sob um fluxo de nêutrons térmicos de $10^{11} \mathrm{n} \cdot \mathrm{cm}^{-2} \cdot \mathrm{s}^{-1}$. Após diferentes tempos de resfriamento e contagem determinou-se: $\mathrm{Mg}, \mathrm{Mn}, \mathrm{Na}$ e K.

b) irradiações longas: as amostras e padrões foram irradiados por oito horas, sob um fluxo de nêutrons térmicos de $10^{13} \mathrm{n} \cdot \mathrm{cm}^{-2} \cdot \mathrm{s}^{-1}$. Após um tempo de decaimento de quatro a cinco dias e um tempo de contagem de cerca de duas horas, determinou-se: Na e K. Após vinte dias de resfriamento e um tempo de contagem de cerca de quinze horas, determinou-se: $\mathrm{Ca}, \mathrm{Co}, \mathrm{Cr}, \mathrm{Fe}, \mathrm{Eu}, \mathrm{Rb}, \mathrm{Sc}$, Se e Zn. O método de AANI foi testado quanto à sua precisão e exatidão por meio da análise dos materiais de referência certificados Citrus-Leaves (NBS SRM 1572), Oyster Tissue (NISTSRM-1566A) e Total Diet (NIST-SRM1548). As medidas da radiação gama emitidas pelos diversos radioisótopos produzidos na irradiação das amostras foram realizadas em espectrômetros de raios gama (Yuyama et al.,1997).

\section{RESULTADOS E DISCUSSÃO}

Os elementos analisados apresentaram uma boa precisão (DPR < 10\%) e exatidão (ER < 10\%), com exceção do selênio (Se) que apresentou valores em torno de $11 \%$ no material de referência Total Diet (Tabela 1), que possui características nucleares favoráveis para a sua ativação. Embora o selênio tenha uma abundância isotópica baixa $(0,9 \%)$, apresentou uma seção de choque de ativação com nêutrons térmicos de 51,2 barns, valor esse bastante alto. $\mathrm{O}^{75} \mathrm{Se}$ é formado pela reação nuclear ${ }^{74} \mathrm{Se}(\mathrm{n}, \mathrm{g}){ }^{75} \mathrm{Se}$. A obtenção de concentrações para os elementos analisados no presente trabalho, com boa precisão e exatidão permite dizer que os resultados são plenamente confiáveis, pois foram quantificados não somente pelos padrões sintéticos dos elementos de interesse, como também pelo material de referência Oyster Tissue, que possui valores certificados para todos os elementos minerais analisados.

Verificou-se que, de um modo geral, a composição centesimal do palmito (Tabela 2) está dentro do que se conhece para outras hortaliças comestíveis, sendo similar à do repolho e do aspargo (FIBGE, 1978), exceto quanto ao teor de glicídio que é menor no palmito. O palmito não é boa fonte de pro- teína, com valores em torno de 1 a $2 \%$ e tão pouco de lipídios, com valores inferiores a $0,5 \%$, sendo portanto, de baixo valor calórico. As calorias dos vegetais, dentre eles os palmitos, variam com a percentagem de glicídios presentes, mas no geral, o alto teor de água e celulose, os colocam em uma classe de baixo teor calórico, podendo ser utilizados como alimentos dietéticos.

Em comparação com trabalhos existentes na literatura relativo a outras palmeiras (Villachica et al., 1996) o palmito de pupunheira apresenta valores inferiores no que se refere a proteínas, energia e teor de fibra. Quando se compara à mesma espécie, os resultados obtidos neste trabalho são semelhantes quanto ao teor de umidade, proteína, cinzas e lipídios, diferindo no aporte calórico, fibra e glicídio (Araújo, 1993). Obviamente há de se considerar vários aspectos ao se comparar os resultados, uma vez que há a influência dos tratos de cultivos, espécie selecionada, local de plantio, idade das palmeiras e metodologia utilizada, especialmente no que se refere ao teor de fibra. Dependendo da metodologia utilizada podese subestimar as concentrações de fibra, com consequente reflexo no aporte energético, uma vez que a fração nifext, ou glicídio, é obtida pela subtração das demais frações, ou seja, umidade, proteína, lipídio, cinza e fibra. Um outro elemento não essencial presente no pal-

Tabela 1. Resultados obtidos na certificação de padrões sintéticos com os materiais de referência OYSTER TISSUE (NIST-SRM 1566 ${ }^{\mathrm{a}}$ ) e TOTAL DIET (NIST-SRM 1548). São Paulo, IPEN-CNEN, 1995.

\begin{tabular}{lccccccccc}
\hline \multicolumn{3}{c}{ OYSTER TISSUE } & \multicolumn{7}{c}{ TOTAL DIET } \\
\hline Elementos Valor obtido & $\begin{array}{c}\text { Valor } \\
\text { esperado }\end{array}$ & D.P.R. & E.R. & Valor obtido & $\begin{array}{c}\text { Valor } \\
\text { esperado }\end{array}$ & D.P.R. & E.R. & $\begin{array}{c}\text { Branco } \\
(\boldsymbol{\mu} \mathbf{g} / \mathbf{g})\end{array}$ \\
\hline $\mathrm{Ca}$ & $1540 \pm 145$ & $1690 \pm 190$ & 9,4 & 8,9 & $1710 \pm 161$ & $1740 \pm 70$ & 9,4 & 1,7 & $109 \pm 34$ \\
$\mathrm{Co}$ & $0,54 \pm 0,03$ & $0,57 \pm 0,11$ & 5,6 & 5,3 & & - & & & $\begin{array}{c}2,1 \pm 0,2 \\
\text { (ngg-1) }\end{array}$ \\
$\mathrm{Cr}$ & $1,41 \pm 0,04$ & $1,43 \pm 0,46$ & 2,8 & 1,4 & & & & & $0,22 \pm 0,05$ \\
$\mathrm{Fe}$ & $531 \pm 8$ & $539 \pm 15$ & 1,5 & 1,5 & $31,5 \pm 0,9$ & $32,6 \pm 3,6$ & 2,9 & 3,4 & $3,2 \pm 0,6$ \\
$\mathrm{~K}$ & $8323 \pm 556$ & $7900 \pm 470$ & 6,7 & 5,4 & $6120 \pm 168$ & $6060 \pm 280$ & 2,7 & 1,0 & - \\
$\mathrm{Mg}$ & $1259 \pm 77$ & $1180 \pm 170$ & 6,1 & 6,7 & $568 \pm 54$ & $556 \pm 27$ & 9,5 & 2,2 & - \\
$\mathrm{Na}$ & $3899 \pm 29$ & $4170 \pm 130$ & 0,7 & 6,5 & $6252 \pm 188$ & $6250 \pm 188$ & 3,0 & 0,03 & $13,4 \pm 0,3$ \\
$\mathrm{Rb}$ & $3,0 \pm 0,1$ & $(3)$ & 3,3 & & $5,0 \pm 0,1$ & $(4,8)$ & 2,0 & & \\
$\mathrm{Se}$ & $2,32 \pm 0,08$ & $2,21 \pm 0,24$ & 3,4 & 5,0 & $0,274 \pm 0,03$ & $0,245 \pm 0,005$ & 10,9 & 11,8 & - \\
$\mathrm{Zn}$ & $898 \pm 10$ & $830 \pm 57$ & 1,1 & 8,2 & $30,0 \pm 0,3$ & $30,8 \pm 1,1$ & 10,0 & 2,6 & $0,15 \pm 0,04$ \\
\hline
\end{tabular}


mito em quantidades relevantes foi o fitato (hexafosfato de mioinositol) (Tabela 2), um dos fatores antinutricionais que interferem na baixa biodisponibilidade dos cátions bivalentes, em especial o zinco, formando um complexo insolúvel (Fairweather-Tait, 1992). Entretanto, com a cocção houve redução da concentração de fitato na ordem de $31,7 \%$, quando comparado com o palmito in natura (Tabela 2). Dada a carência de informações disponíveis na literatura quanto a esse elemento, a informação permanece como registro para futuras comparações.

Verificou-se a superioridade da concentração de potássio em relação aos demais elementos minerais essenciais à nutrição, seguido do cálcio e magnésio (Tabela 3). Em relação aos micro-elementos minerais zinco, ferro e selênio apresentaram as maiores concentrações. Reportando à literatura, observa-se que os teores de cálcio assim como zinco, aqui analisados, apresentaram concentrações superiores aos encontrados por Araújo (1993), mesmo trabalhando com a mesma raça de pupunheira. Entretanto, o teor de cálcio se assemelha ao do repolho (FIBGE, 1978) e palmito de pupunheira (Villachica et al.,1996). As considerações inferidas para a composição centesimal quanto a variação das concentrações, dentro de uma mesma raça, são também válidas para as variações observadas para os elementos minerais.

Além dos elementos minerais mais comumente conhecidos, o palmito de pupunheira é também fonte de outros elementos minerais importantes. $\mathrm{O}$ cobalto, sendo um constituinte da vitamina $B_{12}$, é um elemento traço essencial aos animais e ao homem. A concentração de 187,7 e 273,0 mg\% de cobalto no palmito in natura e cozido (Tabela 3), está abaixo da ingestão diária das dietas de São Paulo (Maihara, 1996) e abaixo das doses tóxicas. Para atingir a dose de $10 \mathrm{mg}$ de cobalto que apresenta efeitos tóxicos fatais (Angeres \& Heinrich, 1988) necessitaria-se de 5,3 toneladas de palmito in natura e 3,7 toneladas de palmito cozido, o que é um volume improvável de ser consumido em um dia. Dos elementos minerais analisados, os considerados como não es-

Tabela 2. Composição centesimal e teor de fitato do palmito de pupunheira in natura e cozido em 100g da parte comestível. Manaus, INPA, 1995.

\begin{tabular}{lccc}
\hline \multicolumn{1}{c}{ Composição } & $\begin{array}{c}\text { Palmito in } \\
\text { natura }\end{array}$ & Palmito cozido & $\begin{array}{c}\text { Recomendação } \\
\text { (NAS, 1989) }\end{array}$ \\
\hline Umidade & 91,5 & 93,5 & - \\
Proteína (g) & $1,5 \pm 0,01$ & $1,5 \pm 0,05$ & 63 \\
Glicídio (g) & 1,9 & 2,3 & - \\
Lipídio (g) & $0,3 \pm 0,01$ & $0,2 \pm 0,01$ & - \\
Cinza (g) & $1,0 \pm 0,08$ & $0,3 \pm 0,02$ & - \\
Fibra solúvel (g) & 0,0 & 0,6 & - \\
Fibra insolúvel (g) & 3,8 & 1,6 & - \\
Calorias (kcal) & 16,3 & 17,0 & 2900 \\
Fitato (mg) & $554,7 \pm 0,4$ & $379,1 \pm 4,4$ & - \\
\hline
\end{tabular}

${ }^{1}$ Considerando a recomendação para um homem adulto (25-50 anos).

Tabela 3. Teor de elementos minerais no palmito de pupunheira in natura e cozido em 100 g da parte comestível. Manaus, INPA, 1995.

\begin{tabular}{lccc}
\hline & $\begin{array}{c}\text { Palmito In } \\
\text { natura }\end{array}$ & Palmito Cozido & $\begin{array}{c}\text { Recomendação } \\
\text { (RDA, 1989) }\end{array}$ \\
\hline Ca $(\mathrm{mg})$ & $42,4 \pm 12,9$ & $42,9 \pm 3,7$ & $800(\mathrm{mg} / \mathrm{d})^{1}$ \\
$\mathrm{Fe}(\mu \mathrm{g})$ & $233,7 \pm 14,5$ & $265,2 \pm 28,6$ & $10(\mathrm{mg} / \mathrm{d})^{1}$ \\
$\mathrm{~K}(\mathrm{mg})$ & $193,6 \pm 4,8$ & $127,8 \pm 0,7$ & $2000(\mathrm{mg} / \mathrm{d})^{1}$ \\
$\mathrm{Na}(\mathrm{mg})$ & $0,10 \pm 0,01$ & $0,11 \pm 0,01$ & $500(\mathrm{mg} / \mathrm{d})^{1}$ \\
Zn $(\mu \mathrm{g})$ & $497,2 \pm 55,1$ & $367,2 \pm 5,8$ & $15(\mathrm{mg} / \mathrm{d})^{1}$ \\
Se $(\mu \mathrm{g})$ & $2,1 \pm 0,2$ & $2,8 \pm 0,5$ & $70(\mu \mathrm{g} / \mathrm{d})^{1}$ \\
$\mathrm{Mg}(\mathrm{mg})$ & $3,4 \pm 0,1$ & $2,2 \pm 0,1$ & $350(\mathrm{mg} / \mathrm{d})^{1}$ \\
$\mathrm{Br}(\mu \mathrm{g})$ & $830,4 \pm 5,8$ & $434,2 \pm 5,8$ & $1(\mathrm{mg} / \mathrm{kg})^{2}$ \\
$\mathrm{Co}(\mathrm{ng})$ & $187,8 \pm 11,05$ & $273,0 \pm 0,1$ & $3(\mu \mathrm{g} / \mathrm{d})^{3}$ \\
$\mathrm{Cr}(\mathrm{ng})$ & $8,6 \pm 0,2$ & $2,8 \pm 0,1$ & $50-200(\mu \mathrm{g} / \mathrm{d})^{1}$ \\
Eu $(\mathrm{ng})$ & $47,0 \pm 0,7$ & $16,9 \pm 4,5$ & - \\
$\mathrm{Rb}(\mu \mathrm{g})$ & $315,2 \pm 3,2$ & $433,5 \pm 34$ & $1,74-5,7(\mathrm{mg})^{5}$ \\
\hline
\end{tabular}

${ }^{1}$ Considerando a recomendação para um homem adulto (25-50 anos);

${ }^{2}$ Recomendação WHO (1972);

${ }^{3}$ Recomendação em termos de vitamina $\mathrm{B}_{12}$

${ }^{4}$ Recomendação Gibson et al. (1984);

${ }^{5}$ Recomendação Clemente et al. (1977).

senciais em maiores concentrações, foram bromo $(\mathrm{Br})$, rubídio $(\mathrm{Rb})$ e európio (Eu). Com a cocção o teor de bromo e európio se reduziram, mas o mesmo não é verdadeiro para rubídio (Tabela 3). O bromo é um dos elementos traço mais abundantes na biosfera. Entretanto, não há nenhuma evidência da essencialidade do mesmo para os seres humanos, animais e para as plantas (Underwood, 1977). A ingestão diária aceitável para brometo é de $1 \mathrm{mg} / \mathrm{kg}$ de peso corpóreo (WHO, 1972). O que implica em dizer que um homem adulto, de $70 \mathrm{~kg}$, neces- sitaria consumir $8,4 \mathrm{~kg}$ de palmito para atingir o nível recomendado. Apesar de alguns estudos, a essencialidade do rubídio $(\mathrm{Rb})$, ainda não foi comprovada (Davie \& Coleman, 1988). O interesse biológico pelo rubídio também é estimulado pela relação com o potássio e pela concentração elevada nos tecidos humanos. Valores quanto a ingestão dietética foram estimados em $1,7 \mathrm{mg} /$ dia (Gibson et al., 1984) a 5,7 mg/dia (Clemente et al., 1977). Com a concentração média de $(315,2$ e 433,5 $\mu \mathrm{g} \%)$ de rubídio no palmito in natura e cozi- 
do, estes poderiam colaborar respectivamente em (18,5 e 25,5\%), considerando as recomendações de $(1.700 \mu \mathrm{g} / \mathrm{dia})$.

No geral, verificou-se que a cocção do palmito reduziu as concentrações de $\mathrm{K}, \mathrm{Zn}, \mathrm{Mg}, \mathrm{Br}, \mathrm{Cr}$ e Eu e elevou as concentrações de $\mathrm{Fe}$, Se, Co e Rb (Tabela 3). As concentrações de fitato, cinza, fibra insolúvel e lipídio foram reduzidas e a umidade, glicídio, fibra solúvel e energia elevadas (Tabela 2). As concentrações de proteína, $\mathrm{Ca}$ e $\mathrm{Na}$ foram mantidas. No que se refere aos elementos minerais, alguns deles foram perdidos durante o processo de cocção e outros se elevaram, provavelmente em decorrência da desidratação e pela incorporação de contaminantes provenientes de utensílios utilizados. Entretanto, há poucos relatos na literatura, a não a ser a perda de potássio após a cocção (Underwood, 1977).

Concluiu-se portanto, que o palmito é uma olerícola hipocalórica, com teores expressivos de fibras e elementos minerais como potássio, cálcio, magnésio e outros elementos traço importantes, podendo contribuir nas dietas com restrição calórica, assim como compor a alimentação da população Manauara, pelo seus constituintes em elementos minerais e fibra alimentar.

\section{LITERATURA CITADA}

ANGERES, J.; HEINRICH, R. Cobalt. In: SEILER, H.G.;SIGEL, H. (Eds.) Handbook on toxicity of inorganic compounds. New York: Marcel Dekker Inc., 1988. p. 251 - 264.

ARAÚJO, L.M. Aproveitamento industrial e caracterização físico-química de palmito de pupunha (Bactris gasipaes H.B.K.). Manaus: INPA/UFAM, 1993. 50 p. (Tese mestrado).

ASP, N.G.; JOHANSSON, C.G.; HALLMER, H.; SILJESTROM, M.A. A Rapid enzymatic assay of insoluble and soluble dietary fiber. Journal Agricultural Food Chemistry, v. 31, p. 476 - 482, 1983.

ASSOCIATION OF OFFICIAL ANALYTICAL CHEMISTS (AOAC). Official methods of analysis. 16 ed. Washington, 1995. p. 1 - 23.
BONANCCINI, L.A. Produza palmito: a cultura da pupunha. Cuiabá: SEBRAE-MT, 1997. 100 p.

CHATT, A.; DANG, H.S.; FONG, B.B.; JAYAWICKREME, C.K.; MACDOWELL, L.S.; PEGG, D.L. Determination of trace elements in food by neutron activation analysis. Journal Radioanalytical Nuclear Chemistry, v. 1, n. 124, p. 65 - 77, 1988.

CLEMENT, C.R.; MORA URPÍ, J. Pejibaye palm (Bactris gasipaes, Arecaceae): multi-use potential for the lowland humid tropics. Economic Botany, v. 41, n. 2, p. 302 - 311, 1987.

CLEMENTE, G.F.; ROSSI, L.G.L.; SANTARONI, G.P. Trace elements intake and excretion in the Italian population. Journal Radioanalytical Chemistry, v. 37, p. 549 - 58, 1977.

DAVIE, R.J.; COLEMAN, I.P.L. Rubidium. In: SEILER, H.G; SIGEL, H. (Eds.) Handbook on toxicity of inorganic compounds. New York: Marcel Dekker Inc., 1988. p. 567 - 570.

DUTRA DE OLIVEIRA, J.E.; MARCHINI, J.S Ciências nutricionais. $1^{\circ}$ ed. São Paulo: Sarvier, 1998. 403 p.

FAIRWEATHER-TAIT, S.J. Bioavailability of trace elements. Food Chemistry, v. 43, p. 213 217, 1992.

FISKE, D.H.; SUBBAROW, Y. The colorimetric determination of phosphorus. Journal Biological Chemistry, v. 66, p. 375, 1925.

FUNDAÇÃO INSTITUTO BRASILEIRO DE GEOGRAFIA E ESTATÍSTICA (FIBGE). Estudo Nacional de Despesas Familiares: Consumo Alimentar. Dados preliminares. Tabelas selecionadas. Rio de Janeiro, 1978. 208 p.

GIBSON, R.S.; MAC DONALD, A.C.; NARRUBEZ, O.B. Dietary trace elements intakes of a selected samples of free-living Canadium elderly women. IN: INTERNATIONAL CONFERENCE ON NUCLEAR METHODS IN ENVIRONMENTAL AND ENERGY RESEARCH, 50., Porto Rico, 1984. Proceedings... Porto Rico, 1984. p. 226 - 27.

HAZZEL, T. Mineral in foods: dietary source, chemical forms, interactions, bioavailability. World Review Nutrition Diet, v. 46, p. 1 - 123, 1985.

KERR, L.S.; CLEMENT, R.; CLEMENT, C.R.; KERR, W.E. Cozinhando com a pupunha. $1^{\circ}$ ed. Manaus: INPA, 1997. 95 p.

LAJOLO, F.M.; MARQUES, U.M.L.; FILISETTI-COZZI, T.M.C.C.; McGREGOR, I. Chemical composition and toxic compounds in Rapeseed (Brassica napus, L.) cultivars grown in Brazil. Journal Agricultural Food Chemistry, v. 39, p. 1933 - 1937, 1991.
MAIHARA, V.A. Avaliação do conteúdo de elementos essenciais e tóxicos em dietas de crianças e idosos pelo método de análise por ativação com nêutrons. São Paulo: USP, 1996. 150 p. (Tese doutorado).

NATIONAL ACADEMY OF SCIENCE (NAS). Recommended Dietary Allowances (RDA). 10 ed. Washington, 1989. 284 p.

NISHIKAWA, M.A.N.; MORO, J.R.; BANDEL, G. Cultura da pupunha para produção de palmito. Piracicaba: ESALQ, 1998. 31 p. (Série Produtor Rural 6).

THOMPSON, D.B.; ERDMAN, J.R., J.W. Phytic acid determination in soybeans. Journal Food Science, v. 47, p. 513 - 517, 1982.

UNDERWOOD, E.J. Trace elements human and animal nutrition. 14 ed. Academic Press: London, 1977. 545 p.

VILLACHICA, H; CARVALHO, J.E.U.; MULLER, C.H.; DÍAZ, C.S.; ALMANZA, M. Frutales y hortalizas promisorios de la Amazônia. Tratado de Cooperacion Amazônica. Lima: Secretaria Pro-tempore, 1996. 367 p.

WORLD HEALTH ORGANIZATION (WHO). Pesticide residues in food. Technologic Report. Service. Genova: Série WHO, 1972. n. 502.

YUYAMA, K. Avaliações de algumas características agronômicas para extração de palmito de estipe principal, das 110 progênies de pupunheira inermes. IN: Horticultura brasileira, 35, Foz do Iguaçú 1995. Resumos... Foz do Iguaçú: SOB, 1995. p. 122.

YUYAMA, K. Comportamento de 34 acessos de pupunheiras selecionadas por meio de número de perfilhos e precocidade para produção de palmito. IN: ENCONTRO DE PESQUISADORES DA AMAZÔNIA "ECODESENVOLVIMENTO DA AMAZÔNIA", 8., Porto Velho, 1996, Porto Velho. Anais...Porto Velho: UNIR, 1996. p. 127.

YUYAMA, L.K.O.; AGUIAR, J.P.L.; MACEDO, S.H.M.; GIOIA, T.; YUYAMA, K.; FÁVARO, D.I.T.; AFONSO, C.; VASCONCELOS, M.B.A.; COZZOLINO, S.M.F. Determinação dos teores de elementos minerais em alimentos convencionais e não convencionais da região Amazônica pela técnica de análise de ativação com nêutrons. Acta Amazônica, Manaus, v. 27, n. 3, p. 183 - 96, 1997.

\section{AGRADECIMENTOS}

Ao CNPq e ao INPA pelo suporte financeiro. Ao Dr. Raul de Queiroz Guerra pela tradução do resumo. 